\title{
“Características Clínicas da Ansiedade Infantil frente a Situação Odontológica"
}

Dra. Lilian Rucks Varvaki Rados Cirurgiã Dentista - Especialista em Odontopediatria

\begin{abstract}
RESUMO
Foi realizado um estudo clínico, observando-se o comportamento de 54 crianças com idades que variavam entre os 04 e 09 anos de idade e que buscavam atendimento odontológico.

Se consideraram os comportamentos apresentados até o momento do início do atendimento odontológico.

As crianças em idade pré-escolar mostraram maior apego à mãe e maior tendência a chorar, como maneira de se negar ao atendimento. As crianças de idade escolar manifestavam a sua recusa ao tratamento através de atitudes interruptivas.
\end{abstract}

\section{SUMMARY}

This paper studied the behavior of children with age betwen 04 and 09 years old, that look for dental care.

It was presented a list of actitudes more significant to young children and older children.

\section{INTRODUÇÃO}

O Odontólogo que atende crianças deve ter presente em seu cotidiano, que está tratando com indivíduos em intenso e ativo processo de desenvolvimento físico, intelectual e emocional.

Este processo que caracteriza as crianças nos exige conhecimentos de cada etapa de seuldesenvolvimento, para compreender melhor, ajudar e dar a criança uma resposta adequada à situação odontológica.

A visita ao Odontopediatra deveria ser vista como um processo de rotina da saúde, como é costume com o médico pediatra. Com freqüência, a primeira visita odontológica é um episódio traumático, o que causa uma conexão Dentista-Sofri- mento, que predispõe as crianças a apresentar condutas ansiosas ou temerosas, segundo sua idade e nível de maturidade emocional.

O Dentista deve observar constantemente a conduta da criança e estar preparado para adequar um programa de aproximação, no caso de detectar alguma alteração na resposta, frente a situação odontológica.

O objetivo deste trabalho é descrever condutas observáveis que a criança pode apresentar, quando se enfrenta com o ambiente odontológico, com o fim de estabelecer uma pauta de observação que permita avalar quais condutas são as mais características nas diferentes idades, e que importância podem ter como manifestações de ansiedade.

\section{REVISÃO DA LITERATURA}

Crescimento e amadurecimento psicológico envolvem um processo de formação de padrões de conduta com normas generalizadas para grupos etários, cada criança tem um ritmo e estilo que the são próprios, o que formam sua individualidade.

A criança pode apresentar amplas oscilações de conduta entre limites normais, como passar da agressão à complacência, do progresso à regressão. Alguns comportamentos dependem, principalmente da educaçăo, porém nunca o ensino poderá produzir efeito, se o orga-

* Trabalho apresentado como requisito para a conclusão do curso de Especialização em Odontopediatria na Faculdade de Odontologia da Universidade do Chile 
nismo não está preparado para ser ensinado.

Segundo Piaget, a ação humana consiste em um mecanismo contínuo e perpétuo de reajuste e equilíbrio, - que se alcança "quando a reflexão compreende que sua função característica não é contradizer, mas sim, proceder $\theta$ interpretar a experiência" (32).

A tensão que experimenta uma criança a qual se exige demasiado, ou que não compreende 0 que se espera dela, pode provocar um desvio da tendência de conduta fora de seu curso normal $(4,7,22)$.

O medo e a ansiedade são sentimentos desagradáveis, e que de uma maneira muito geral podem ser definidos como uma resposta antecipada interna a intuição de uma situação perigosa, ou um acontecimento desagradável $(4,13)$.

O medo é uma resposta a objetos e estímulos definidos reais ou imaginários (4), ao contrário da ansiedade que se caracteriza por ser um estado emocional mais difuso, com um "foco" menos preciso.

O organismo da criança durante o período de amadurecimento emocional, se encontra em "estado de alerta" constante, por estar enfrentando situações desconhecidas em sua rotina diária $(4,13,30)$.

Conger (4), considera, segundo a teoria do aprendizado, que os estimulos capazes de provocar ansiedade podem ter origem na identificação de situações onde foram provocados fortes sentimentos de medo.

Posteriormente, com o passar destes acontecimentos provocadores, desencadeiam-se os sentimentos desagradáveis associados com a situação inicial.

No caso particular do pré-escolar, a situação pode tornar-se mais aguda, já que estas crianças têm a tendência a desenvolver medos irracionais, como temor a situações desconhecidas, sofrer algum dano ou ser abandonado $(2,5,12,13)$.

Alguns autores coincidem ao considerar a ansiedade, como uma característica presente no comportamento da criança que deve ser vista como resposta normal e saudável em muitas situações, cujo objetivo é manter a integridade física e emocional do indivíduo $(4,13)$.

Para cada situação, há um nível ótimo de ansiedade necessária e desejável, pois este sentimento é o motor para a iniciativa da criança na busca do domínio de situações $(30)$.

Pode ocorrer que o estado de ansiedade alcance um nivel superior a capacidade de adaptação e integração do organismo, dando lugar a respostas incompatíveis com o equilf́brio físico e psíquico da criança $(4,13)$, determinando condutas inadequadas ou de desajuste a situação que se está vivenciando.

Condutas típicas de desajuste ou inadequadas, são a exagerada agressividade ou o mau rendimento no ambiente escolar $(4,13)$.

A conduta inadequada da criança pode surgir como conseqüência do tipo de relação pai-filho, tal como castigos físicos e psíquicos, privações afetivas, restrições severas, trocas frequentes do trato dos pais, exigências muito elevadas de normas de conduta, estimulações negativas e ásperas, separação dos pais. Estes estímulos que afetam frontalmente a criança e que desencadeiam nela uma ansiedade superior a sua capacidade adaptativa, passam a ser emocionalmente paralizadores, levando a criança a ter respostas inadequadas a uma conduta construtiva e estável $(4,13,30)$.

\section{CARACTERÍSTICAS DO} COMPORTAMENTO ANSIOSO DA CRIANCCA FRENTE A SITUAÇẨO ODONTOLÓGICA

Baldwin (10) propõe que por mais estressante ou desagradável que seja uma situação na rotina de uma criança, esta responde enfrentando-a. Fazer frente a esta situação desagradável ou desconhecida gera ansiedade, que inclui processos mentais, emocionais e resposta de comportamento externo $(2,24)$.

Chambers (30) propõe que a posição do dentista na educação de seu paciente jovem, além do enfoque de prevenção e manutenção da saúde oral, deveria também ser dirigido a auxiliar a criança a ajustar sua ansiedade, a um nivel apropriado pa- ra cada situação.

O comportamento do paciente é a única resposta que o Odontólogo pode observar como manifestação de ansiedade, dai o estabelecimento de parâmetros objetivos de comportamento de crianças em tratamento odontológico, é primordial para o diagnóstico do estado de ansiedade (30).

Jenks (17) afirma que as características de conduta, aberta ou sutilmente demonstradas pelas crianças podem nos orientar, com respeito a como devem ser abordadas as situações pelo Odontólogo.

Os primeiros temores que a criança associa com a Odontologia são produzidos pelo estranho e inesperado, já que qualquer estimulação imprevista dos órgãos sensitivos, produz medo na criança.

Esta sensação de medo pode ser provocada pelo ruído brusco e forte da turbina ou pelas coisas novas $\theta$ cheiros distintos que a criança percebe na consulta $(16,23)$.

Para Losano (13) a ansiedade em uma criança tem um componente subjetivo muito importante, se trata de um temor indefinido; "a criança sente temor, mas não sabe a que".

Os temores subjetivos podem estar baseados em sentimentos e atividades que tenham sido transmitidos pelas pessoas que 0 rodeiam, sem que a criança os tenha experimentado pessoalmente $(2,4,5)$.

Vários autores $(7,9,12,19,29)$ concordam em que as crianças também adquirem temores através da identificação ou da aprendizagem por observação dos membros da casa.

A criança de pouca idade é muito sugestionável $(9,19)$. Se ouve seus pais ou companheiros de brincadeira falarem sobre supostos padecimentos em consulta odontológica, os aceitará como reais e tratará de evitá-los o mais possível $(9,19)$.

É indispensável ressaltar que a atitude positiva dos membros da familia em relação a Odontologia, estimulará a criança a responder favoravelmente $(9,12,28)$.

Outros antecedentes significativos na vida da criança que determinam uma conduta ansiosa na consul- 
ta, relacioam-se com hospitalização para procedimentos cirúrgicos ou para tratamento de enfermidades gerais. Problemas prévios de origem dentária, também terminam levando a criança a resistir ao tratamento odontológico $(10,16,19,20)$.

As manifestações de ansiedade frente a odontologia são várias $(9$, $14,15)$; alguns podem recusar entrar para a consulta, alguns se negam a abrir boca, choram, tremem as mãos, gritam, choram chamando a mãe ou acompanhante. Outros manifestam menos marcadamente sua ansiedade $(9,18,24)$. São em geral tensos, empregam condutas interruptivas como falar animadamente ou manifestam sintomas fisiológicos, tais como palpitações, sudoração, respiração acelerada; senho franzido, tics nervosos e manifestações motoras de recusa $(9,14,15,18,24,26,30)$.

Outro fator de identificação de diferentes niveis de ansiedade em crianças, é o tipo de choro que elas apresentam (10).

Esbahc (18) descreveu quatro tipos de choro em crianças, que são para descarregar a ansiedade frente a situação odontológica:

- Choro Obstinado: É um pranto forte, como o som de uma sirene.

- Choro de Temor: É acompanhado de muitas lágrimas e soluços convulsivos.

- Choro por Dor: Pode ser forte em intensidade, porém é freqüentemente acompanhado de manha.

- Choro Compensatório: É um "zumbido monótono" que a criança emite para amortizar o ruldo da broca.

Diferentes autores concordam com a afirmação de que a ansiedade é um sentimento natural e desejável na criança que vai enfrentar a situação Odontológica (2), porém pode gerar comportamento inadequado, se ultrapassa um nivel ótimo, que é individual.

Os níveis de ajuste, o controle de si mesmo, a confiança nos próprios recursos em situações exigentes, dependem muito da segurança, afeto, confiança dados aos filhos por seus pais (21).

$\mathrm{Na}$ situação Odontológica se deve avaliar pais e filhos para desenvolver um programa destinado a fo- mentar condutas positivas e ter presente que elogios e criticas influem muito sobre as crianças, a tal ponto que os sentimentos positivos gerados na tenra idade influirão sobre futuras atividades Odontológicas $(12,28)$.

As pessoas que trabalham com crianças tem um papel muito importante em modelar o caráter e personalidade de seus pacientes. Cada profissional pode contribuir com algo bom para o processo de maturação das crianças e com isto desenvolver sua própria habilidade de manejar a ansiedade fora de casa. $O$ Dentista deve ter uma atitude de apoio ao paciente para conseguir que a ansiedade na visita Odontológica, seja canalizada para uma postura positiva e colaboradora $(24,26$, $30)$.

O Odontopediatra pode ter uma influência importante na evolução emocional da criança, pois as experiências que ela tiver em uma consulta Odontológica servirão para enfrentar experiências semelhantes em outras situações (30).

\section{Proposição do Problema}

De tudo que encontramos em nossa Revisão de Literatura é possivel constatar que as crianças manifestam de diferentes maneiras sua recusa ao atendimento Odontológico.

O comportamento é bastante variável e depende de múltiplos fatores $(1,8,9,14)$, que terminam por impedir o bom êxito do atendimento Odontológico.

No caso de crianças que apresentam condutas ansiosas frente ao Odontopediatra, é importante a observação das manifestações desta conduta, anterior a introdução de uma técnica de manejo condutual $(11,31)$. esta observação deve ser - mais objetiva possível para que se possa avaliar corretamente os progressos alcançados, portanto, se deve estabelecer quais são realmente as condutas que devem ser modificadas. $O$ objetivo da manifestação de conduta é proporcionar experiências de aprendizagem que promovam no individuo condutas socialmente aceitáveis (11).
Kazdin descreve as principais características de enfoque condutual de um programa modificador da conduta, baseando-se nos princípios de condicionamento operante:

1. Observação direta da conduta-objetivo da troca e sua cuidadosa avaliação, anterior ao programa, o que se conhece como "Linha Base" ou "Taxa Operante".

2. Determinar a amplitude de execução da conduta a modificar e o grau de troca que se requer.

3. Avaliação cuidadosa do efeito do programa que se está aplicando. A troca condutual se reflete ao comparar a conduta durante o programa com a conduta estabelecida na Linha Base.

\section{MATERIAL E MÉTODO}

Este trabalho foi realizado na Policlínica Dental da Força Aérea do Chile e no Serviço de Urgência do Hospital Roberto del Rio, entre as crianças que solicitam atendimento Odontológico.

Foram observadas inicialmente oito crianças na Policlínica Dental do Hospital da $\mathrm{FACH}$, para determinar uma pauta de observação da conduta dos pacientes no ambiente Odontológico.

Os registros foram feitos com descrições amplas e uso de linguagem cotidiana das condutas que naturalmente ocorreram quando o paciente ingressou na clínica OdontoIógica.

Se teve cuidado de trabalhar com crianças cujas idades variam entre 4 e 9 anos. Este grupo inicial não se inclui no estudo.

As condutas observadas se agrupam segundo as notas descritivas e se definem cuidadosamente os conceitos (Linha Base), estabelecendose 6 categorias (anexo no. 1), o que se fazia na ficha de observação (anexo n: 2).

Em ansiedade mínima se agrupam as crianças com reações normais, relaxadas e com relação independente com a mãe, além de cooperadoras com as ordens do dentista.

A ansiedade moderada representa aquelas crianças que caminhavam 
TABELA N: 1

N: de Crianças Observadas (Total 56)

\begin{tabular}{|c|c|}
\hline $\begin{array}{l}\text { Pré-escolares } \\
4-6 \text { anos }\end{array}$ & $\begin{array}{l}\text { Escolares } \\
7-9 \text { anos }\end{array}$ \\
\hline $\begin{array}{ll}H R R & F A C H \\
11 & 13\end{array}$ & $\begin{array}{ll}H R R & F A C H \\
18 & 14\end{array}$ \\
\hline TOTAL 24 & 32 \\
\hline
\end{tabular}

devagar, com expressão séria no rosto, tentando ocultar-se, não falavam, com independência da companhia de sua mãe, e que não se submetiam as ordens do dentista.

Ansiedade alta foi conceituada quando as crianças tentavam opor-

\section{TABELA № 4}

Análise de $X^{2}$ considerando as crianças com ansiedade minima e a soma das ansiedades moderadas e alta no caminhar.

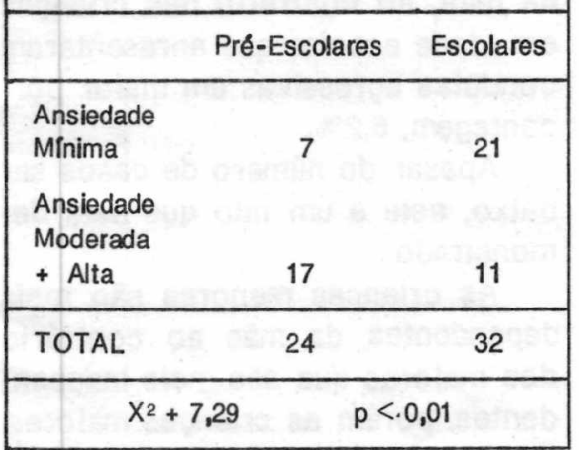

se, expressando de várias formas sua recusa ao atendimento OdontoIógico.

\section{TABELA NN 5}

Análise de $\mathrm{X}^{2}$ considerando as crianças com ansiedade moderada $e$ alta em vocalizaçăo.

\begin{tabular}{|c|c|c|}
\hline & Pré-Escolares & Escolares \\
\hline \multicolumn{3}{|l|}{ Ansiedade } \\
\hline Moderada & 2 & 6 \\
\hline \multicolumn{3}{|l|}{ Ansiedade } \\
\hline Alta & 10 & 2 \\
\hline TOTAL & 24 & 32 \\
\hline & 6,80 &, 01 \\
\hline
\end{tabular}

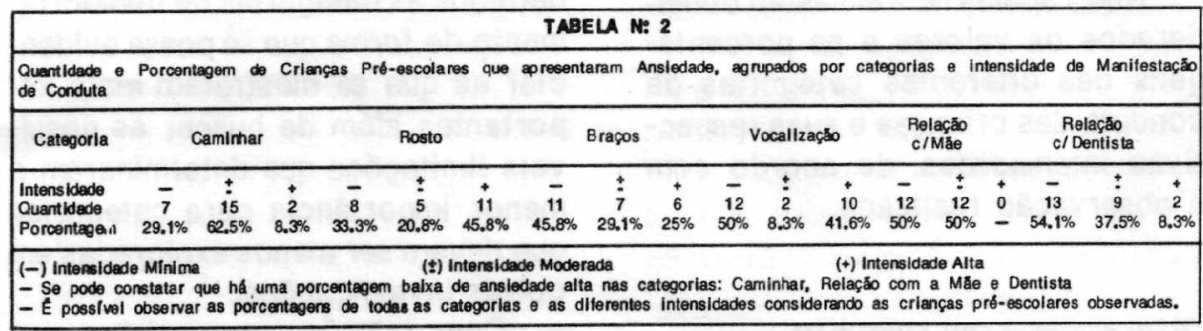

\section{TABELA N: 3}

Quentidade e Porcentagem de Crianças Pré-escolares que apresentaram Ansiedade, agrupados por categorias e intensidade de Manifestaçắo da Conduta

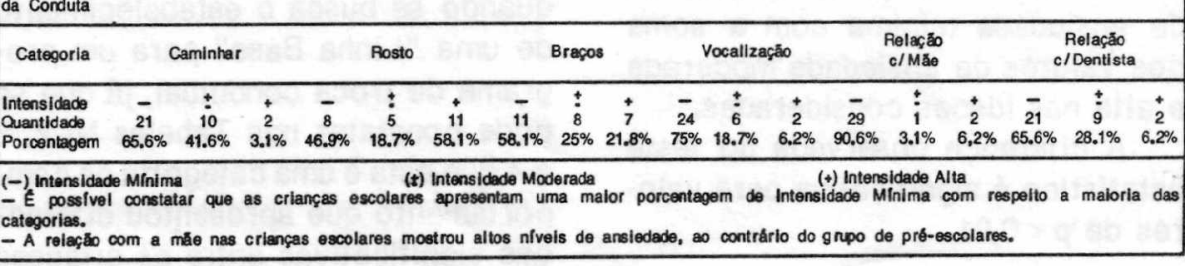

Pela comparação destas Tabelas é possivel identificar algumas diferenças com respeito as porcentagens apresentadas.

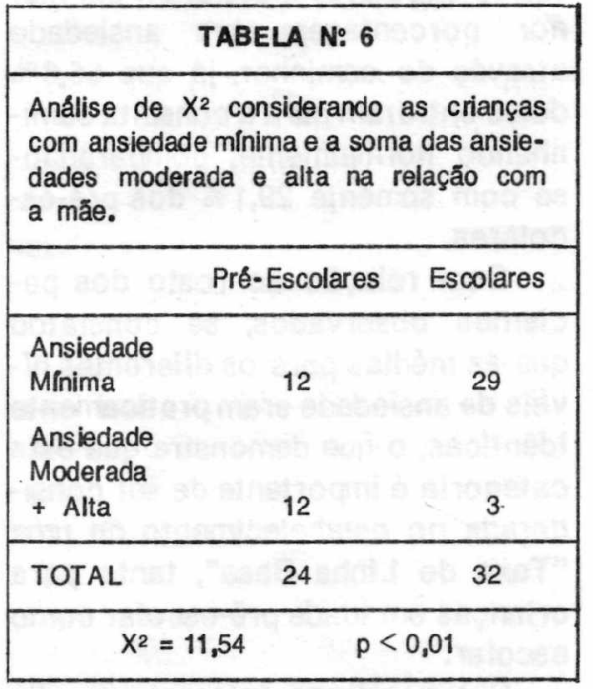

Se determinou qual o intervalo de tempo mais apropriado para os fins desta investigação, ficando este

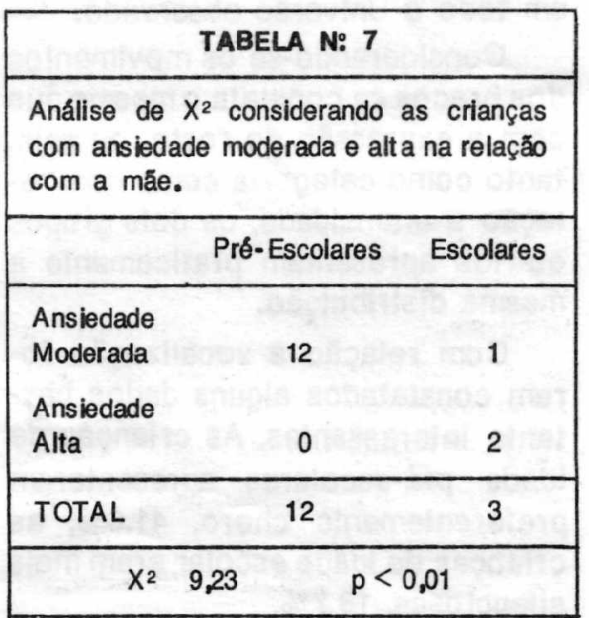

do momento em que se abria a porta do consultório até a criança sentarse na cadeira para iniciar o tratamento.

Deste modo, são suprimidos elementos modificadores de conduta como instrumental, procedimentos e personalidade do Odontólogo.

O observador foi sempre o mesmo e se colocava numa posição onde era possivel observar todos os movimentos da criança, e tomava a atitude de uma "filmadora" que tudo observa, porém em nada interfere.

Foram observadas 56 crianças que variavam entre os 4 e 9 anos e que foram separadas em grupos etários:

- Criança pré-escolar, com idade entre 4 e 6 anos.

- Criança escolar, com idade entre 7 e 9 anos (Tabela n: 1).

Os resultados obtidos foram organizados e tabulados para serem analisados estatisticamente. Se empregou o Test $X^{2}$ para buscar diferenciais significativas entre:

- Categorias de condutas ansiosas observadas nas crianças pré-escolares e escolares.

- Também se buscou di ferenciais significativas entre as intensidades de manifestação de conduta ansiosa em crianças pré-escolares e escolares. 


\section{RESULTADOS}

Nas Tabelas N. 2 e 3 estão considerados os valores e as porcentagens das diferentes categorias de conduta das crianças e suas respectivas intensidades, de acordo com a observação realizada.

\section{Diferenças com respeito ao Caminhar}

Quando se comparam os valores de ansiedade mínima com a soma dos valores de ansiedade moderada e alta nas idades consideradas.

A diferença observada no teste estatístico é significativa para valores de $p<0,01$.

\section{Vocalização:}

Quando se comparam as ansiedades moderadas e alta entre as faixas etárias consideradas neste trabalho.

A diferença estatística observada é significativa para um valor de $\mathbf{p}<0,01$.

\section{Relação com a Mãe:}

Nesta categoria foi possível constatar diferenças significativas quando se considera os valores de ansiedade mínima com a soma dos valores de ansiedade moderada e alta para as diferentes idades. Valor de $p<0,01$.

Também foram demonstradas diferenças significativas entre a comparação das médias de ansiedade moderada e alta nas diferentes idades. Valor de $p<0,01$.

Todos os demais valores obtidos foram submetidos ao mesmo Teste Estatístico $\left(X^{2}\right)$, porém em nenhum foi possivel demonstrar diferenças significativas com relação a idade escolar e pré-escolar, como se pode constatar pela semelhança dos valores médios das categorias de comportamento e intensidades consideradas neste trabalho. Comparar os valores das Tabelas 2 e 3.

\section{DISCUSSÃo}

Com o fim de aproximar a dis- cussão dos achados deste trabalho com os objetivos propostos, consideramos as categorias de comportamento de forma que se possa evidenciar as que se mostraram mais importantes além de buscar as possiveis limitações que determinaram a menor importância para categorias que devem ser menos exploradas em outras investigações.

Com relação ao caminhar das crianças constatamos que esta característica deve ser considerada quando se busca o estabelecimento de uma "Linha Base" para um programa de troca condutual, já que se pode constatar nas Tabelas № 2, 3 e 4 que esta é uma categoria de comportamento que apresentou diferenças significativas entre as crianças de diferentes idades considerandose a ansiedade mínima e a soma de ansiedade moderada e alta. Além disto, os escolares mostraram em menor porcentagem sua ansiedade através do caminhar, já que $65,6 \%$ deles entraram para a consulta caminhando normalmente, comparandose com somente $29,1 \%$ dos pré-escolares.

Com relação ao rosto dos pacientes observados, se constatou que as médias para os diferentes niveis de ansiedade eram praticamente idênticas, o que demonstra que esta categoria é importante de ser considerada no estabelecimento de uma "Taxa de Linha Base", tanto para crianças em idade pré-escolar como escolar.

Outro achado interessante diz respeito as diferentes intensidades de manifestação de ansiedade que também foi praticamente a mesma em todo o Universo observado.

Considerando-se os movimentos dos braços se constata o mesmo que com a expressão do rosto, ou seja, tanto como categoria como com relação a intensidade, os dois grupos etários apresentam praticamente a mesma distribuição.

Com relação a vocalização foram constatados alguns dados bastante interessantes. As crianças de idade pré-escolares apresentaram preferentemente choro, $41,6 \%$, as crianças de idade escolar eram mais silenciosas, $18,7 \%$.
Baseando-se nestes dados se poderia deduzir que as crianças de idade pré-escolar apresentam um nivel de ansiedade mais alto que as crianças de idade escolar (Ver Tabela № 5), porém é importante considerar que aos 7 anos a maturidade da personalidade de uma criança é maior, - que permite que ela reprima seu choro, ao contrário de uma criança de 4 anos.

Esta constatação permite propor a vocalização como uma categoria para o estabelecimento da "Linha Base", porém suas intensidades devem ser avaliadas de acordo com - grupo etário que se está considerando.

A relação da criança com a mãe mostrou ser a categoria com maiores diferenças para o estabelecimento da "Taxa de Linha Base".

$\mathrm{Na}$ Tabela № 6 se constata que as crianças em idade escolar são mais independentes da mãe que os pré-escolares. Porém na Tabela № 7 se constata que as crianças em idade pré-escolar são dependentes da mãe, ao contrário das crianças em idade escolar que apresentaram condutas agressivas em maior porcentagem, 6,2\%.

Apesar do número de casos ser baixo, este é um fato que está demonstrado.

As crianças menores são mais dependentes da mãe ao contrário dos maiores que são mais independentes, porém as crianças maiores, quando mani festam comportamentos ansiosos em sua relação com a mãe são mais agressivas.

Levando em consideração a relação da criança com o dentista, se pode constatar pela comparação entre as Tabelas N. 2 e 3 , que os valores médios são praticamente idênticos, 0 que permite considerar esta categoria e suas diferentes intensidades no estabelecimento de uma "Taxa de Linha Base" independentemente da idade da criança que se está observando.

Nos parece importante destacar que as observaçōes das diferentes categorias de ansiedade foram realizadas por um único observador. Kazdin (11) preconiza pelo menos dois observadores diferentes. Esta 
possivel falha no trabalho pode ser solucionada com a proposta de uma próxima investigação, onde as categorias aqui definidas seriam submetidas a comprovação e se julgado necessário se modificariam.

A importância está em propor uma metodologia de observação prévia, quando se necessita implementar um programa de modificação condutual.

É necessário avaliar a conduta qlis se quer trocar por observação da resposta e confronto da situação provocadora de ansiedade, ou seja, registrar o comportamento natural que a criança tem ao enfrentar-se com a clínica odontológica.

O controle de programas de modificação de condutas é realizado pela constatação da troca de conduta inicial do indivíduo, já que o objetivo é modificar a conduta da pessoa e os testes estatísticos estão baseados nas médias dos grupos (11).

Nossas análises estatísticas se justificam por estarem dirigidas ao estabelecimento das condutas mais predominantes na observação de diferenças entre os diferentes grupos etários.

$\mathrm{Na}$ busca de definir condutas observáveis para estabelecer uma linha base do comportamento na situação odontológica, poderfamos orientar as observações para préescolares e escolares.

Com o objetivo de determinar 0 grau de ansiedade e aplicar a técnica adequada ao grupo etário do próprio paciente:

Pré-Escolar

Caminhar

Expressåo do rosto

Movimento de braços

Choro

Dependência da mãe

Relaçăo com o Dentista

\section{CONCLUSÃO}

1. É possivel estabelecer uma "Taxa de Linha Base" do comportamento ansioso das crianças no ambiente odontológico.
2. Se pode propor diferentes categorias para a "Taxa de Linha Base", além de se poder determinar diferentes intensidades dentro das categorias.

3. Existem categorias que são de maior ou menor importância de acordo com a idade da criança.

4. As crianças de idade pré-escolar manifestam mais marcadamente sua ansiedade na relação com a mãe e no choro que apresentam.

5. As crianças em idade escolar apresentam sua ansiedade através da agressividade com a mãe $\theta$ não respondendo as perguntas que Ihes são feitas.

\section{BIBLIOGRAFIA REVISADA}

1. BORDONI, N. - Prevención del Miedo en la Situación Odontopediatrica. Actualidad Odontológica. 4 (2); 44-49, 1980.

2. RIPA, L.W. and BARENIE, Y.T. - "Mane jo de la Conducta Odontológica del Niño". Primera Edición. 4:26, 1984.

3. ROSENZEIG, S., SFORZA, A. and ADDELSTON H.K. - "Children's Attitudes Towards Dentists and Dentistry". J. Dent. Child. 35:129-137, 1968.

4. MUSSEN, P.H. and CONGER, J.; KAGAN, J. - "Desarrollo de la Personalidad en el Niño". Pấg. 397. 1979, México.

5. GALE, EN. - "Fears of the Dental Situaciónn". J. Dent. Res. 51:964-966, 1972.

6. REMPLEIN, H. - "Psicologla Evolutiva. La Primera Edad de la Obstinación".

7. ILLINGWORTH, R.S. - "Los Problemas de los Primeros Años de Vida y su Tratamiento". Universidad de Sheffield, Edinburgh. Pág. 272-280.

8. FORGIONE, A.G. and CLARK, E.R. "Coments on an Empirical Study of the Causes of Dental Fears". J. Dent. Res. Vol. 53, N: 2, March-April, 1974.

9. TRIEGER, N.D.M.D.; and BERNSTEIN, N. M.D. - "Good Child, Bad Tooth". Massachusetts General Hospital. Vol. 16, № 3, 264-270, 1963.

10. BARDWIN, D. Jr. - "And Investigation of Psychological and Behavioral Responses to Dental Extraction in Children". J. Dent Res. 45:1637-1651, 1966.

11. KAZDIN, ALAN E. - "Modificaciones de la Conducta y sus Aplicaciones Prácticas". Editorial El Manual Moderno S.A. Mexico, 1978.

12. SHOBEN, EN. and BARLAND, L. - "An Empirical Study of the Etiology of Dental Fears". J. Clin Psycholog. 10:171-174, 1954.

13. LOZANO, J.A.F. - "Cuadernos de Psicología Infantil y Juvenil". El Problema de la Ansiedad en el Niño". Ediciones Nueva Gente. Vol. 7. Påg. 121-140, 1985.

14. FIRESTEIN, Stephan - "Patient Ansiety and Dental Practice". J.A.D.A. Vol. 93. Pág. 1180-1187, 1976.

15. MARTINEZ, MARIA I. Z y SALCEDO SILVIA, L.B. - "Estudio del Efecto FarmacoIógico en el Tratamiento Odontológico de Niños de Diffcil Mane jo". Trabajo de Perfeccionamiento para Optar al Título de $\mathrm{Ci}$ rujano-Dentista. Facultad de Odontologla, Universidad de Chile, 1981.

16. WILLIAMS, J.M.G. and Others - "Ansciety in the Child Dental Clinical". J. Child Psychol, Psychiat. Vol. 26, № 2, Påg. 305-310, 1985.

17. YENKS, L. - "How the Dentis Behavior Can Influence the Child Behavior". J. Dent. Child. 31:358-366, 1964.

18. ELSBACH, H.G. - "Crying as a Diagnostic Tool". J. Dent. Child. 30:13-16, 1963.

19. GORDON, D.A., TENDAL, Lo and STERLING, E. - "The use of Modeling and Desensibilization in the Treatment of a Child Pacient". Journal of Dentistry for Child. Pág. 22-25, 1974.

20. SERMET, O. - "Emotional Factors in Child Dental Ansciety". J. Child Psychol., Psychiat. Vol. 15, Pág. 313 to 321, 1974.

21. OPPNHEIN, M.N. and FRANK Lo, S.N. "A Behavioral Analysis of the Preschool Child when Introduced to Dentistry by a Dentist or Hygienist". J. Dent Child. 38:317-325, 1971.

22. GESELL, ARNOLD and OTHERS - "The First Five Years of Life, a Guide to the Study of the Preschool Child". New York: Haper Bro., Pág. 29-57, 1940.

23. FINN, S. In. - "Odontologla Pediátrica". Cuarta Edisión. Interamericana, México, 1976, Påg. 14-26.

24. TEUSCHER, GEORGE N. - "The Aplication of Psycology in Pedodontics". Illinois. Påg. 533-538.

25. ADELSAN, RICHARD and GOLDFRIED, M.R. - "Modesing and the Fearful Child Patient". J. Dent. Child Nor-dec, 1970. Påg. 476:489.

26. CROZCTON, WILLIAM - "Child Behavior and the Dental Experience y Dent Child". 1967. 21-218.

27. GHOSE, L.Y. et al: "Evaluation of Subling Support". J. Dent Child 36:35-40 49, 1969.

28. BRAHAM, RAYMOND L. Y MORRIS, MERLE - "Odontologla Pediátrica". Editorial Médica. Panamericana. S.A. 1984. Buenos Aires. Pág. 451-455.

29. MC DONALD, RALPH E. - "Odontologla para el Niño y Adolescente". Editorial Mundi 1971, Buenos Aires. Pág. 29-30.

30. CHAMBERS, Dow. - "Managing the Anscietics of Young Dental Patients". J. Dent Child. Vol. 37, 1970. Påg. 363-367-370-373.

31. GARCIA-GODOY, F.M. - "Parents Dentist and Child Classification for Behavior Management in the Dental Environement". The Journal of Pedodontics. 10:273-282. 1986.

32. JEAN PIAGET - "Seis Estudios de Psicologla". Ed. Barral (Barcelona), 1984. 